\title{
Power quality improvement using Cuckoo search based multilevel facts controller
}

\author{
B. Srinivasa Rao*, D. Vijaya Kumar** and K. Kiran Kumar*** \\ * Assistant Professor, Dept of EEE, Aditya Institute of Technology and Management, Tekkali, A.P, India \\ ** Professor and Head, Dept of EEE, Aditya Institute of Technology and Management, Tekkali, A.P, India \\ *** Professor, Dept of EEE, Aditya Institute of Technology and Management, Tekkali, A.P, India \\ * Corresponding Author: bsreee2013@gmail.com
}

Submitted : 20/06/2020

Revised : :17/02/2021

Accepted : 24/04/2021

\begin{abstract}
Nowadays, the improvement of power quality is the major concern in power system scenario. These problems are mainly caused due to utilization of different load conditions to the power system. To mitigate these problems, different methods are implemented in the literature. As per the literature analysis, the one of the Flexible AC Transmission System, called unified power quality conditioner (UPQC), plays a key role. The series and shunt controllers of UPQC are designed with 9-level inverters to reduce the harmonic distortions. An instantaneous PQ theory is used to generate the reference signals required for series and shunt controllers along with DQ-transformation analysis. A Cuckoo optimization technique is used to tune the parameters of PI controller in shunt controller to achieve better harmonic distortions and improve power quality. This proposed system is to be tested and verified in MATLAB/SIMULINK.
\end{abstract}

Keywords: Power Quality; Unified power quality conditioner; PI controller; CUCKOO controller; THD, 9-Level Inverter.

\section{INTRODUCTION}

In the present scenario, there are many places that are facing difficulty to access electricity, and some places are connected to grid and receiving electricity up to 10-12 hrs per day. From the past years, the reliability of power system decreases due to harmonics, reactive power effects, and unwanted currents caused by utilization of nonlinear loads. The reasons for these problems are generally due to the utilization of nonlinear loads in consumer end, arc furnaces, and switching conditions in semiconductor switches. Basically, the harmonics and reactive power are major concern in power system, which is associated with grid. A flexible AC transmission system is proposed in this paper to improve the reliability of transmission system and the quality of electrical power by reducing the problems (i.e., harmonics, power factor effects) [1]. To overcome the power quality problems in both voltage and current in the distributed micro grid system, a unified power quality conditioner is considered.

Generally, the load voltage of the system decreases as the load increases, and this load voltage is restored to a nominal value by using suitable closed loop system. This closed loop control system can control the voltage and reactive powers and set back to normal values represented in this paper. To regulate these parameters, the proposed 
system is implemented with FACTS controllers. FACTS controllers offer a great opportunity to regulate transmission parameters.

In this paper, for solving problems in power system, shunt and series APF controllers are used. Series-Shunt Controllers are among the major devices that regulate and control load voltage [2]. Line impedance of the system is identified by using line parameters available in the handbook and literature view. In general system unbalance conditions, system voltage-current is one of the major issues for both utility side and end user side. And also, the control strategy of both series and shunt converters is designed properly. The PI and CUCKOO controllers are used in both controllers to regulate the system errors.

\section{PROPOSED SYSTEM}

The proposed microgrid system is designed for multifeeders to operate loads. In this structure, the loads are considered as linear and nonlinear loads. The problems caused by these different loads are compensated with one of the custom power devices called interline power quality conditioner connected between feeders. The structure of interline unified power quality conditioner is shown in Figure 1. The two converters of the APF are separated by a common DC link voltage. The shunt VSC converter of network is associated with feeder-1, and arrangement VSC converter is associated with feeder-2 [3]. There is a boosting transformer that is associated between series converter and transmission network to keep up the voltage levels. APF can go about as (a) shrewd electrical switch, and (b) it also provides reactive and active powers between grid and microgrid by acting like PFC.

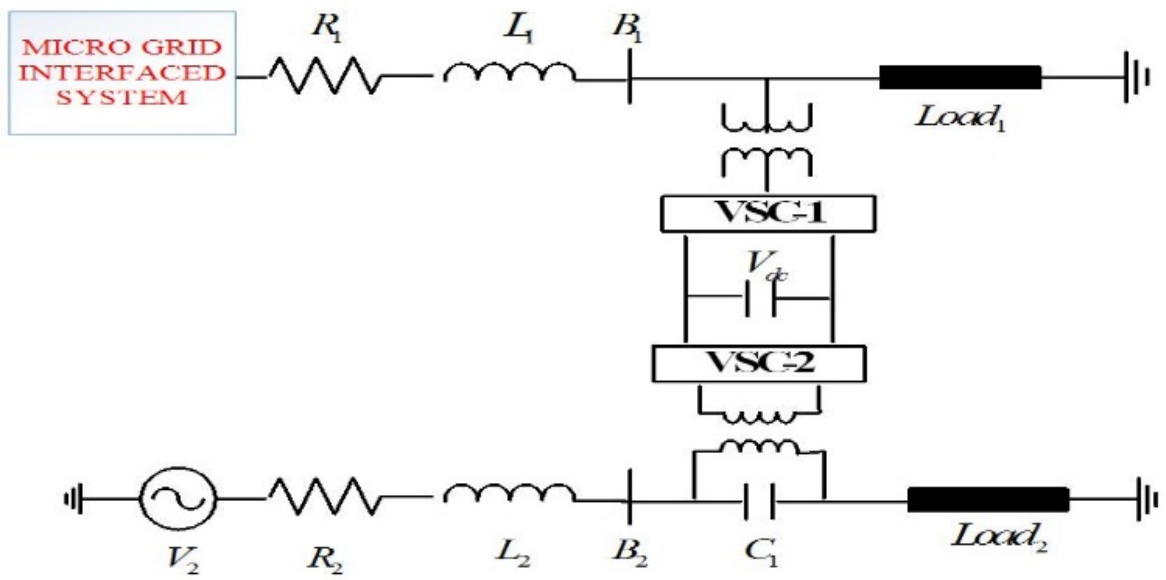

Figure 1. Structure of APF based Distribution System.

\section{Series APF Converter}

As shown in the control diagram, the grid current is transformed into direct and quadrature axis currents. The direct and quadrature axis current components can be used to control the reactive powers of the interconnected system [4]. This DQ-currents are compared with system reference currents to regulate system voltage and frequency.

The stator frequency is controlled by load side converter. In this, the reference frequency is compared with conventional frequency of the generator. With these figures, the frequency varies from $49 \mathrm{~Hz}$ to $51 \mathrm{~Hz}$. And also, an 
ANFIS technique is proposed in this paper to achieve better voltage and frequency controlling [5]. The structure of grid side converter with Cuckoo technique is shown in Figure 2.

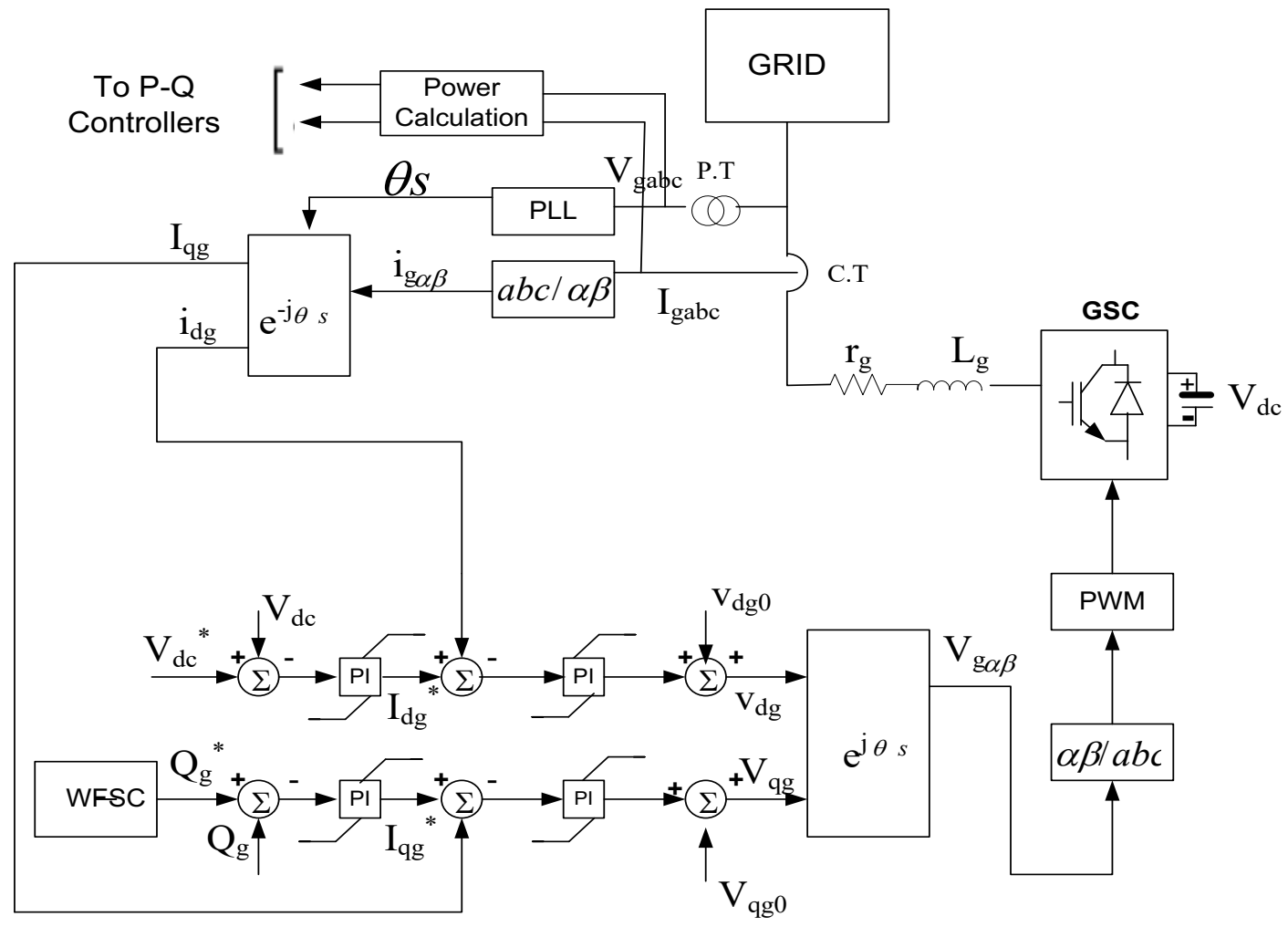

Figure 2. Structure of proposed PSO based GSC control diagram.

\section{Shunt APF controller}

The shunt converter control diagram is designed by using the concept of instantaneous PQ- theory as shown in figure 3. The purpose of PQ theory is to generate the reference current signals, which are required for compensating current harmonics. In this case, the actual load voltage and currents are converted into $\alpha \beta$-coordinates. From these coordinates, the active and reactive powers are to be calculated. These reference powers are compared with rated energy after which they are transformed to reference currents with the assistance of conventional PI controllers [6]. And Inverse Park's transformation is used for getting standard ABC components and carried out to PWM controller to get gate signals.

The real and reactive power expressions for proposed system are shown in expression (1):

$$
\begin{aligned}
& P=v_{\alpha} i_{\alpha}+v_{\beta} i_{\beta}=\tilde{p}+\bar{p} \\
& q=v_{\beta} i_{\alpha}-v_{\alpha} i_{\beta}=\tilde{q}+\bar{q}
\end{aligned}
$$




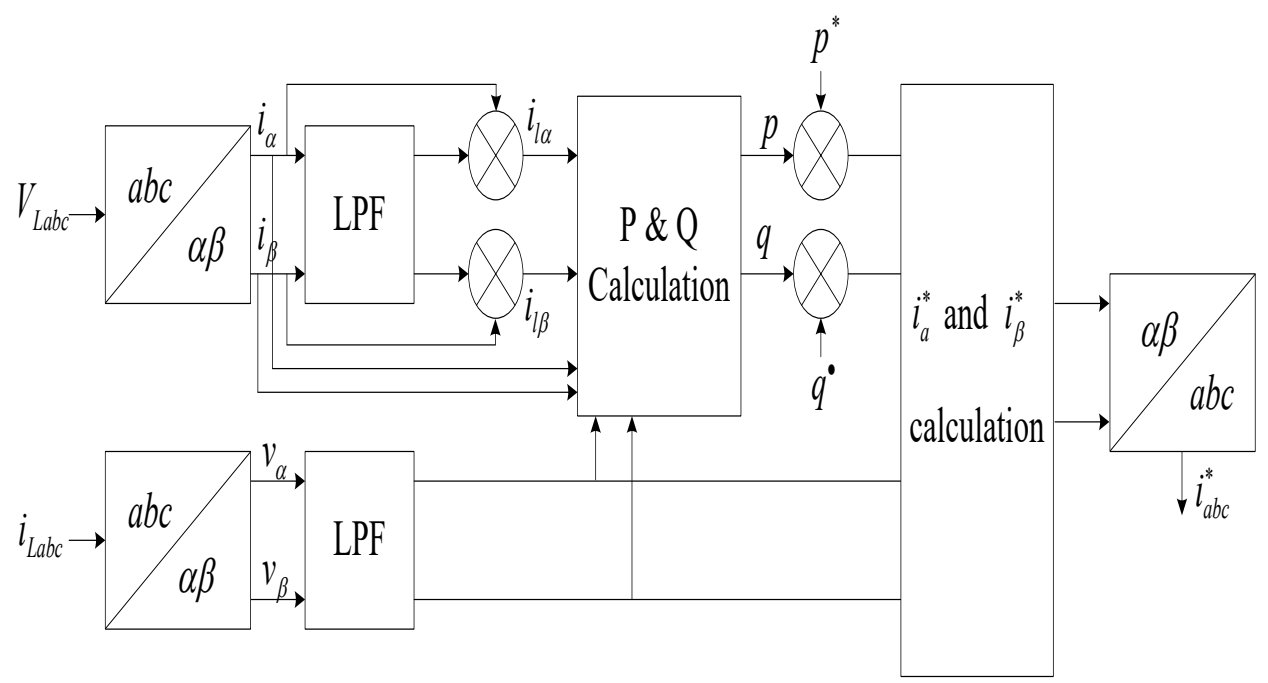

Figure 3. Control structure of the shunt inverter.

\section{NPC Topology}

Figure 4 indicates the topology of the NPC 3-degree inverter with LC filter on the output factor. Every leg has four IGBTs linked in series. The NPC-9L inverter uses split capacitors in collection for DC link and produces 0 voltage degree. For that reason, the voltage drop at the IGBT may be Udc/2; it is one-half of that of the conventional level inverter, wherein Udc is the overall voltage of DC link. This feature makes it extra suitable for the application with higher DC bus voltage [7]. What is more, the NPC inverter has some other favorable abilities consisting of decreasing common-mode voltage and reducing output modern-day ripple for the equal switching frequency compared with the conventional two-stage inverter. As an end result, a smaller output filter is required in comparison to an identical rated-level inverter.

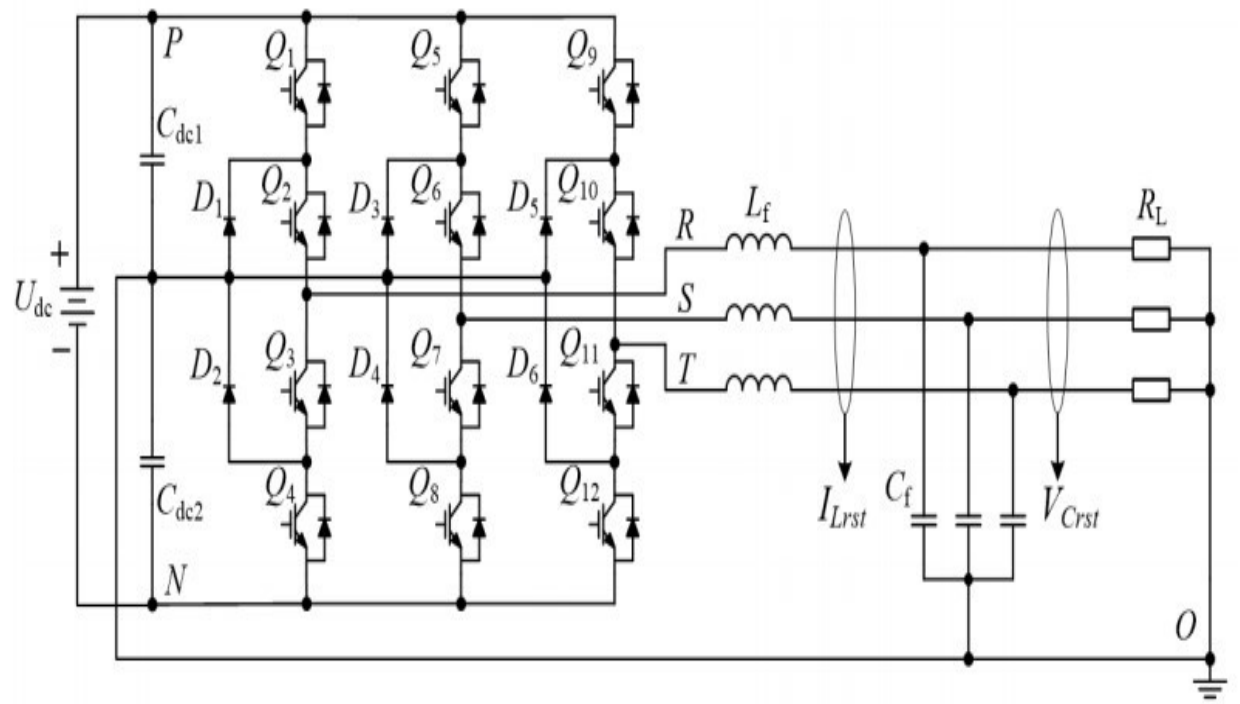

Figure 4. Topology of the NPC three-level inverter. 


\section{Cuckoo Algorithm}

Due to its sound and aggressive reproduction strategies, Cuckoos are fascinating birds. Generally, Cuckoos lay their eggs in communal nests and can do away with other eggs to growing hatching chance in their very own eggs [8]. Female cuckoos search and choose a group of host spices with similar nest web sites and egg traits to their very own and then select the best from these nests.

Cuckoos start looking for the best nest, and this is an important step that has an important role in cuckoo's reproduction method. To search for the best nest and process of food, the Le'vy flight plays a key role. The step length or Le'vy flight distribution is shown as follows:

$S=\alpha_{q}\left(V_{b t}-v_{j}\right) \oplus l e(\lambda)$

Figure 5 shows the flowchart for Le'vy based cuckoo search algorithm. In this, the random initial solution of the voltage and current of solar panel is selected. The fitness of power is calculated as shown in $\mathrm{P}=\mathrm{V} * \mathrm{I}$. The expression for identification of best current parameter is shown as

$$
V_{i}^{t+1}=V_{i}^{t}+\alpha \oplus \operatorname{levy}(\lambda)
$$

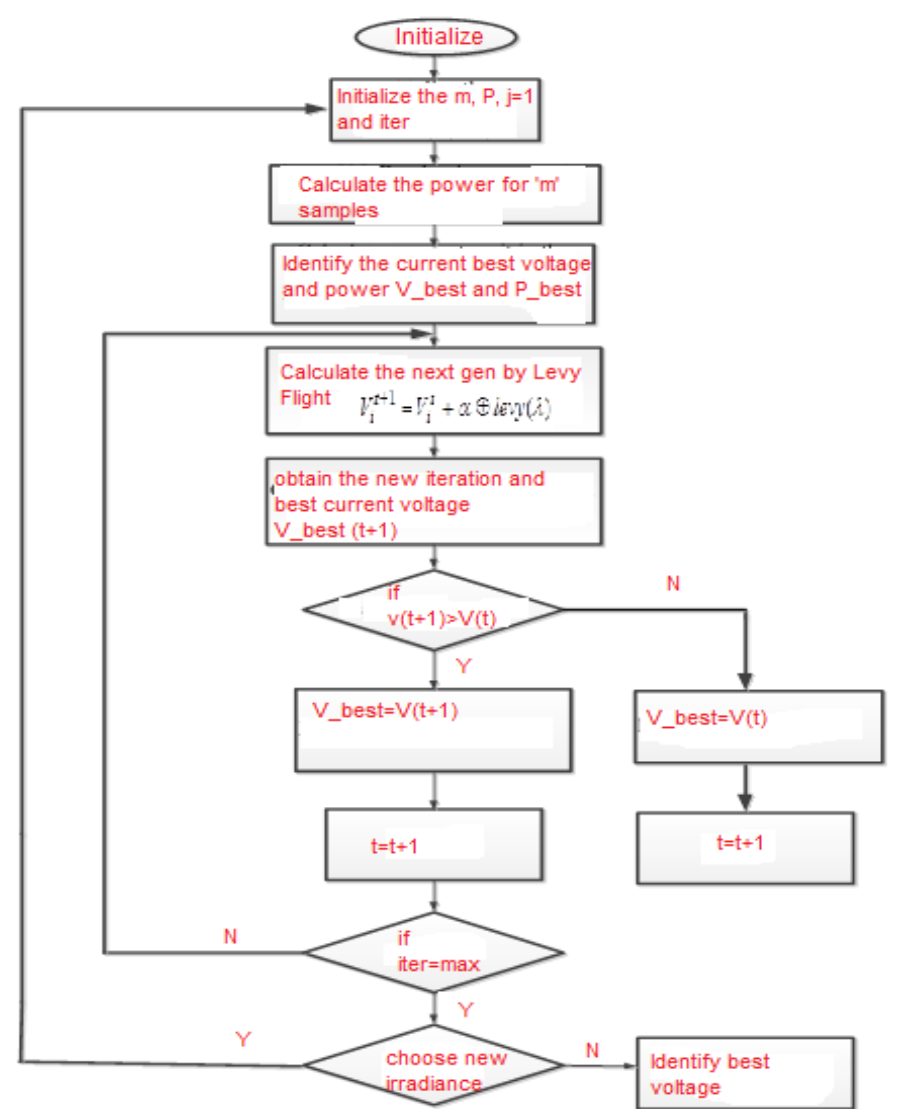

Figure 5. Cuckoo Search Algorithm. 


\section{Fuzzy Controller}

The architecture for fuzzy controller is shown in Figure 6. In order to get better compensation as compared with PI controller, a Mamdani based fuzzy controller is proposed in this paper [9-10]. The given fuzzy inference system is a two-input model; generally, one of the inputs is taken as error between Vdc and Vdcref, and the second input is the rate of change of error. Each input consists of fuzzy set with membership values of $\{\mathrm{MP}, \mathrm{SP}, \mathrm{Z}, \mathrm{SN}$, $\mathrm{MN}$. And it consists of the total number of rules as 25 . After that, a centroid method is used for converting fuzzy set into normal crisp value.

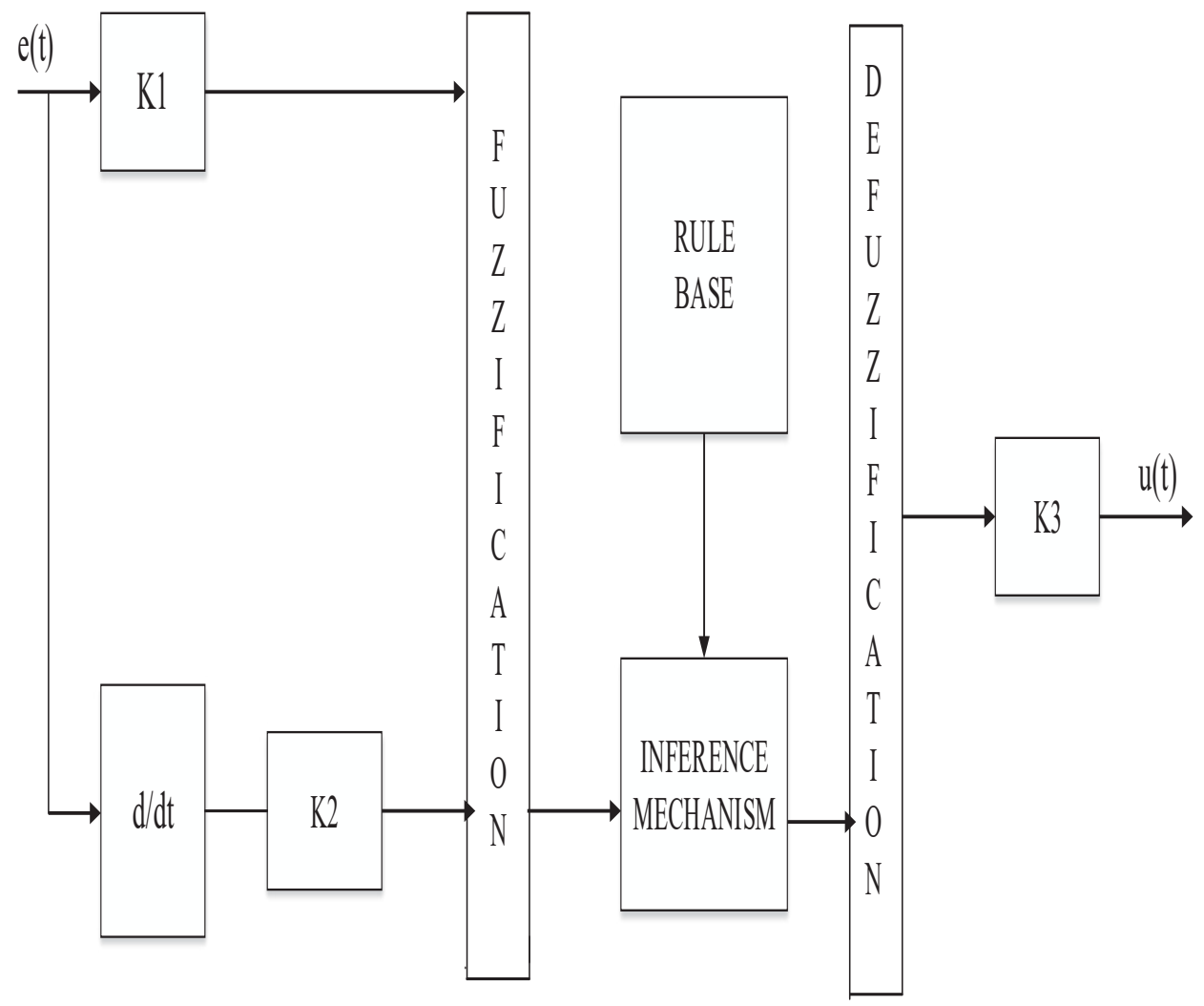

Figure 6. Fuzzy Mamdani System Configuration.

\section{SIMULATION RESULTS \& DISCUSSIONS}

The proposed NPC based shunt and series converter distributed system shown in Figure 1 is implemented in Matlab Environment under to the following controllers: 1) PI controller, 2) Fuzzy Logic Controller, and 3) ANFIS Controller. And also, the simulation results are shown below. 


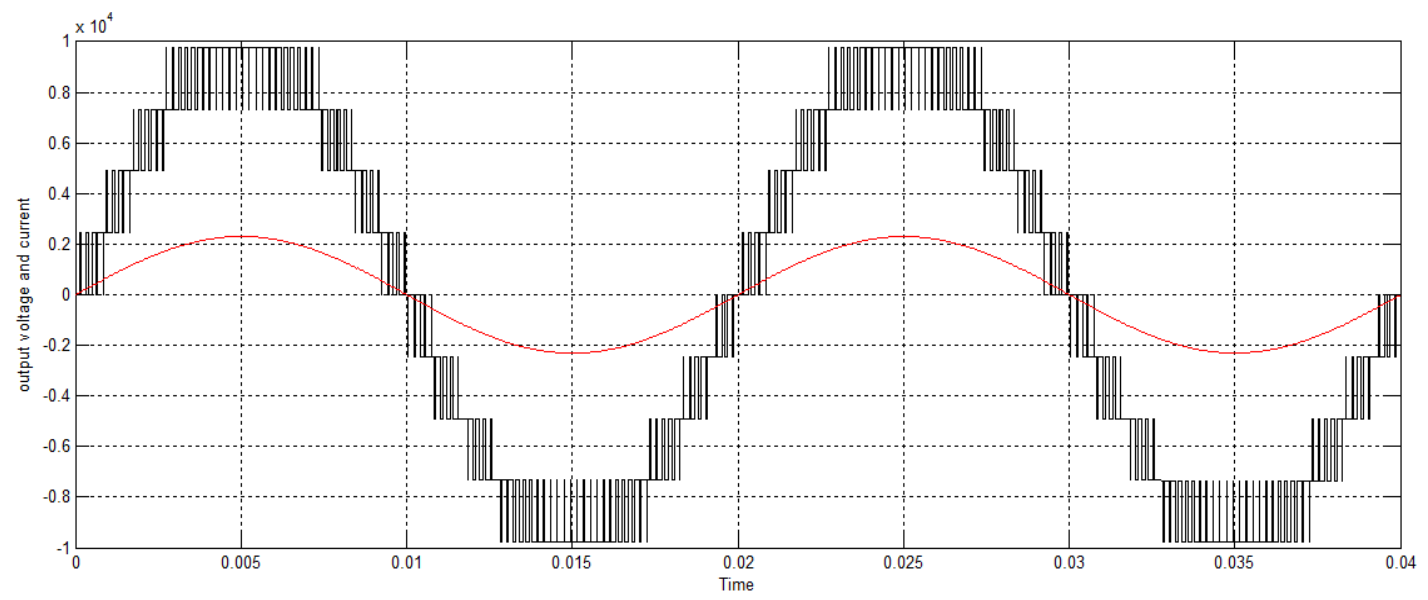

Figure 7. Source Voltage \& Current with Nine Level Series \& Shunt Converter with PI Control System.

Figure 7 shows the simulation result for nine-level inverter voltage and currents. These voltage and currents are measured at Custom Power Device both series and shunt Voltage Source Converters.

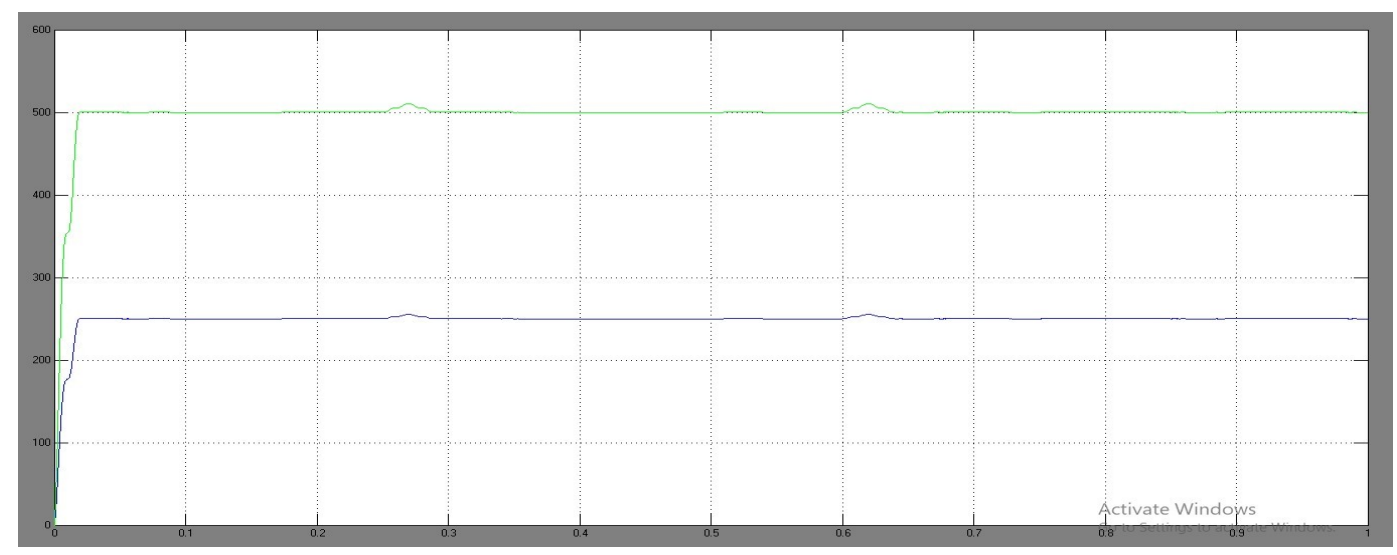

Figure 8. DC voltages of series and shunt converters.

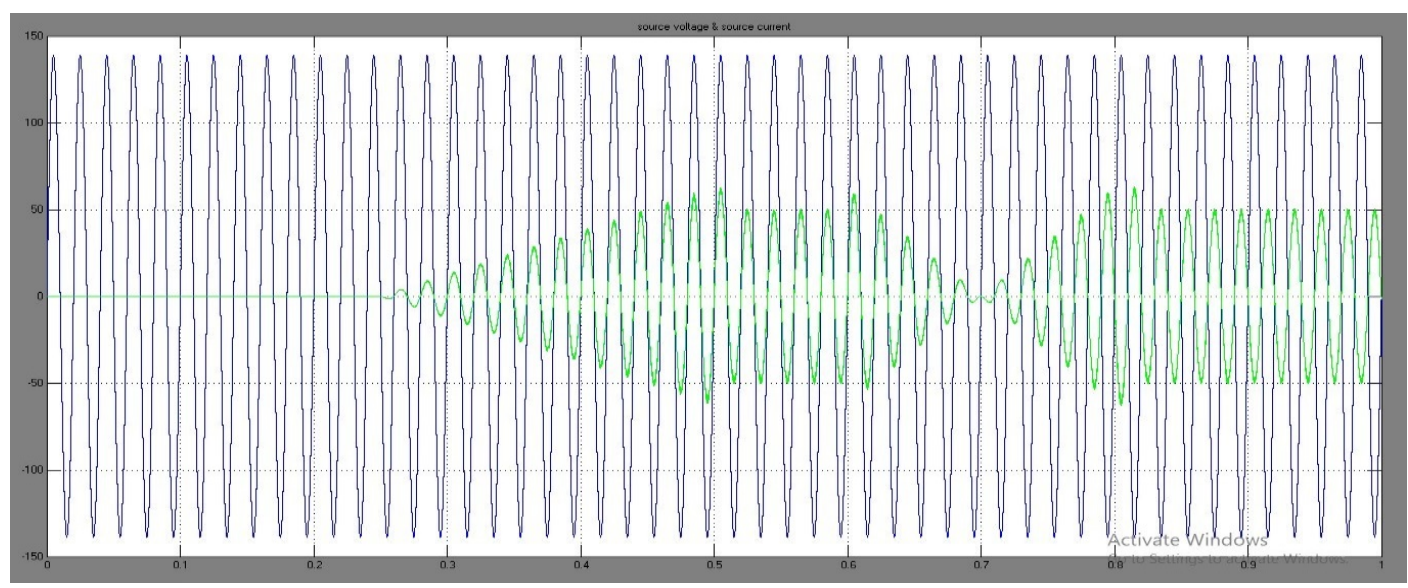

Figure 9. Nine-level voltages of proposed converter. 


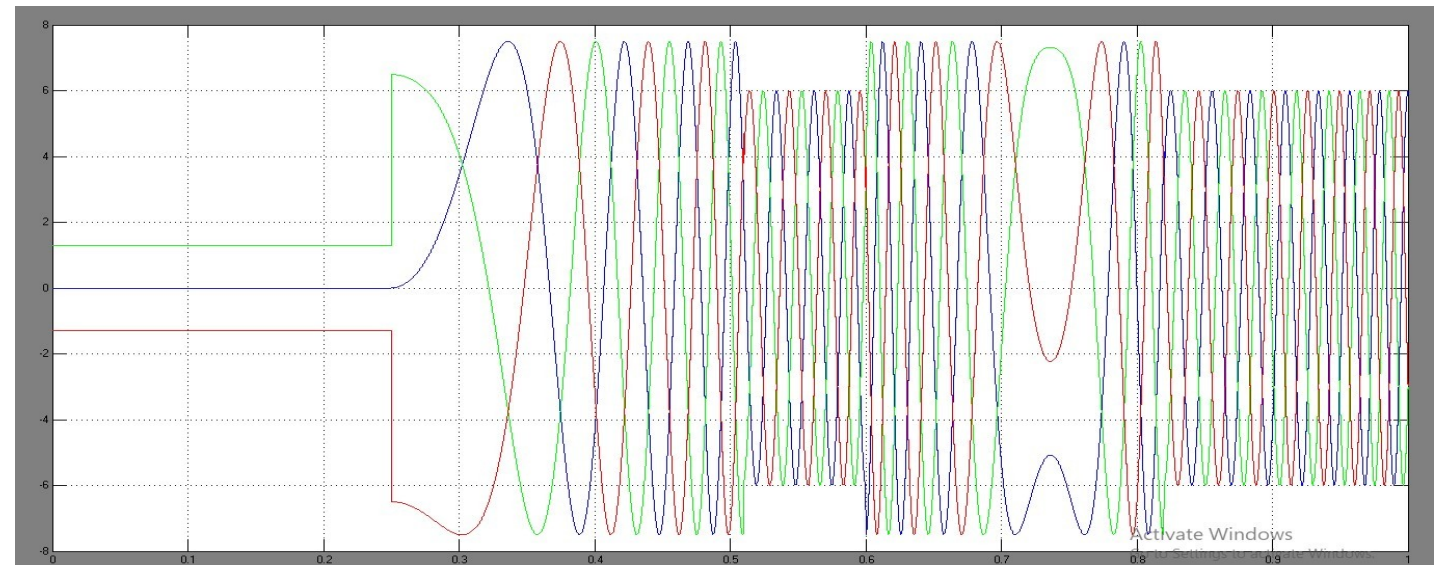

Figure 10. Unbalanced load voltages at motor using PI controller.

Figure 9 shows the simulation result for series active filter current voltage for 3-level NPC controller. From $0 \mathrm{~s}$ to $0.3 \mathrm{~s}$, the series APF is in off state condition, so that there is no compensation during this period, and later, at $\mathrm{t}=0.3 \mathrm{~s}$, the active filters go to turn-on condition, and it gives some compensation. Figure 8 shows the simulation result for the DC-link voltage control of series and shunt converters. The simulation waveform for motor parameters under PI controller is shown in Figure 10.

\section{Case-1: With PI Controller}

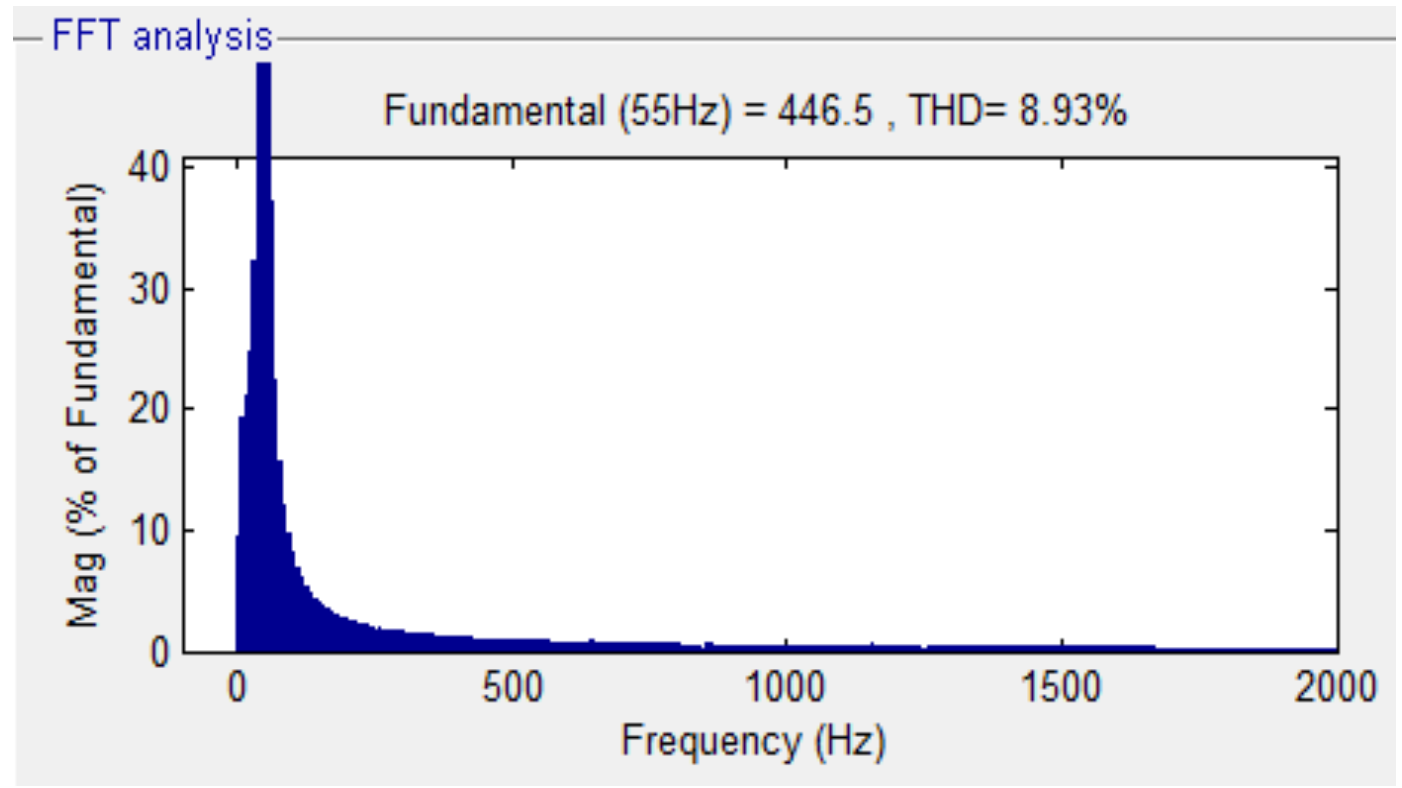

Figure 11. THD for NPC voltage using PI Controller. 


\section{Case-2: With Fuzzy Controller}

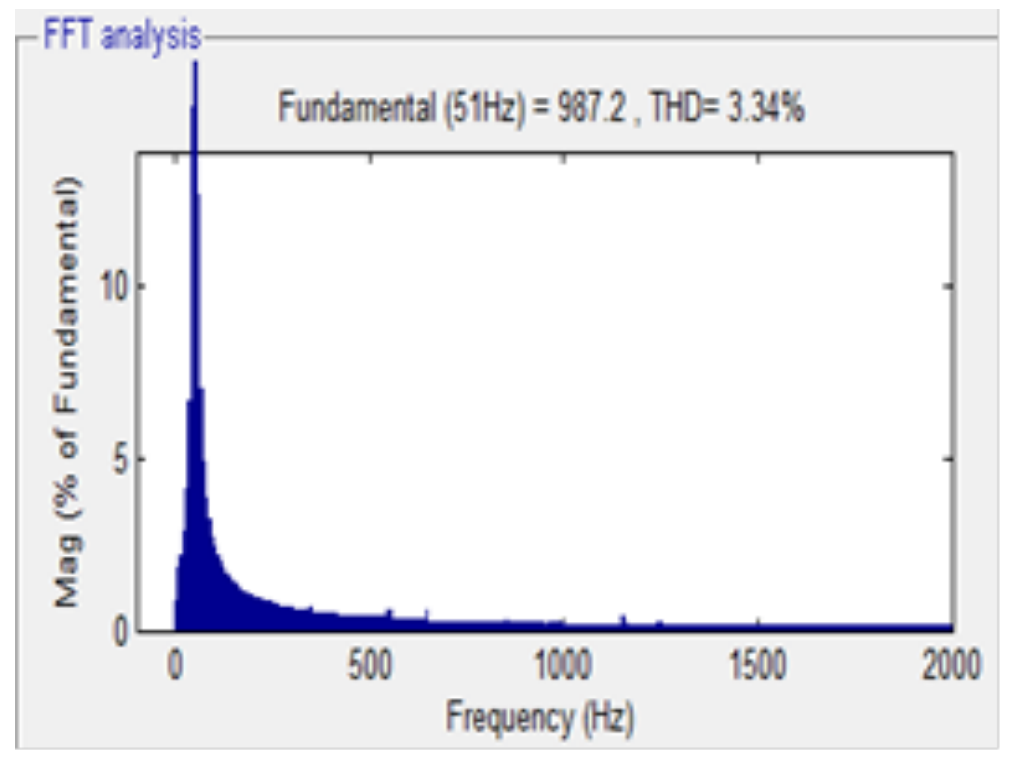

Figure 12. THD for NPC voltage using Fuzzy Controller.

The comparative analysis between the application of PI, Fuzzy, and Cuckoo controller for proposed 9-level NPC Active power filter is done in terms of total harmonic distortion. The harmonic distortion for source current with conventional PI controller is $8.93 \%$, with fuzzy controller being $\%$ and with Cuckoo controller being $3.04 \%$ as shown in Figures 11, 12, and 13.

\section{Case-3: With Cuckoo Controller}

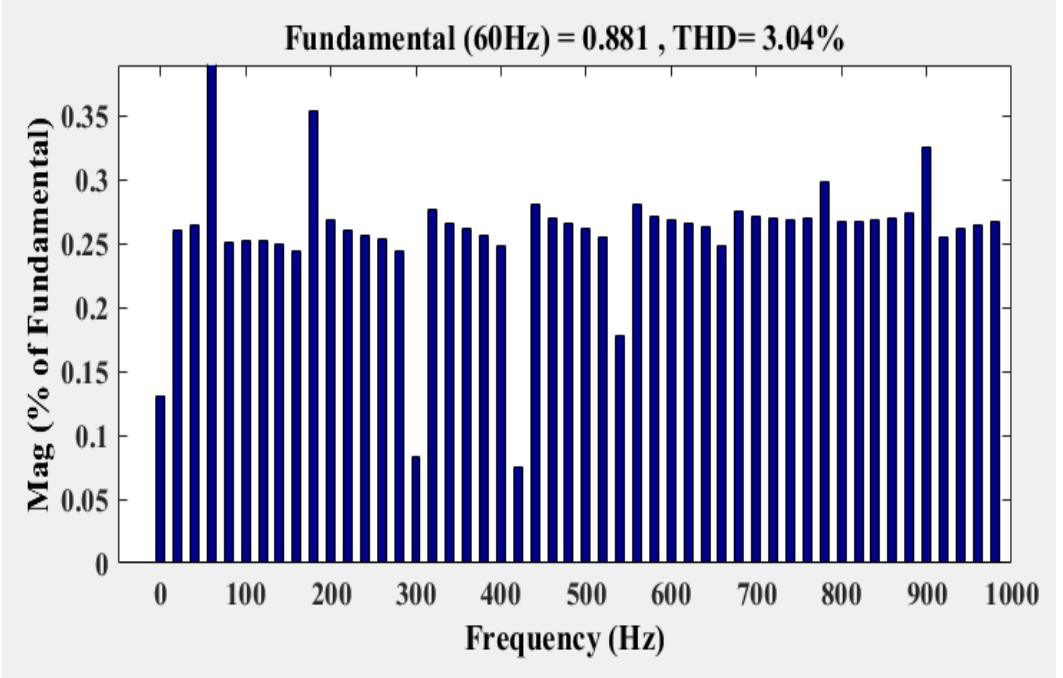

Figure 13. THD for NPC voltage using Cuckoo Controller. 
Table 1. Comparative Analysis for THD.

\begin{tabular}{|c|c|c|c|c|}
\hline \multirow{2}{*}{ S.No } & \multirow{2}{*}{ Parameter } & \multicolumn{3}{|c|}{ THD Analysis (\%) } \\
\cline { 3 - 5 } & & With PI Controller & With Fuzzy Controller & With Cuckoo Controller \\
\hline 1 & Voltage & 4.26 & 2.27 & 1.36 \\
\hline 2 & Current & 8.93 & 3.34 & 3.04 \\
\hline
\end{tabular}

\section{CONCLUSION}

The proposed distributed 9-level NPC based active filters with Cuckoo controller are implanted to improve power quality of the system. The control diagrams for two filters are implemented using DC-link voltage and system parameters. To get better power quality of the proposed system, the control diagrams are implemented by 1) conventional PI Controller, 2) Fuzzy Controller, and 3) Cuckoo Controller. The simulation setup is done for different conditions, and the results are shown. From these results, the Cuckoo based proposed system provides better power quality as compared with conventional PI and Fuzzy controllers.

\section{REFERENCES}

S. J. Park, F. S. Kang, M. H. Lee, and C. U. Kim, "A new single-phase five-level PWM inverter employing a deadbeat control scheme,” IEEE Trans. Power Electron., vol. 18, no. 3, pp. 831-843, May 2003.

V. G. Agelidis, D. M. Baker, W. B. Lawrance, and C. V. Nayar, "A multilevel PWM inverter topology for photovoltaic applications,” in Proc. Int. Symp. Ind. Electron, Jul. 1997, vol. 2, pp. 589-594.

G. J. Su, “Multilevel DC-link inverter,” IEEE Trans. Ind. Appl., vol. 41, no. 3, pp. 848-854, May-Jun. 2005.

M. Calais, L. J. Borle, and V. G. Agelidis, "Analysis of multicarrier PWM methods for a single-phase five level inverter," in Proc. Power Electron. Specialists Conf., 2001, vol. 3, pp. 1351-1356.

C. T. Pan, C. M. Lai, and Y. L. Juan, "Output current ripple-free PWM inverters," IEEE Trans. Circuits Syst. II, Exp. Briefs., vol. 57, no. 10, pp. 823-827, Oct. 2010.

T. C. Neugebauer, D. J. Perreault, J. H. Lang, and C. Livermore, "A six-phase multilevel inverter for MEMS electrostatic induction micro-motors," IEEE Trans. Circuits Syst. II, Exp. Briefs, vol. 51, no. 2, pp. 49-56, Feb. 2004.

A. Nabae, I. Takahashi, and H. Akagi, “A new neutral-point-clamped PWM inverter,” IEEE Trans. Ind. Appl., vol. IA-17, no. 5, pp. 518-523, Sep. 1981.

Shahrzad, Seyedali Mirjalili, Saremi, \& Andrew Lewis" Grasshopper optimization algorithm: theory and application." Advances- in Engineering- Software (2017), pp: 30-47.

N. S. D. Arrifano, V. A. Oliveira, R. A. Ramos, "Design and Application of Fuzzy PSS for Power Systems Subject to Random Abrupt Variations of the Load", 0-7803-8335-4/04/\$17.00 02004 AACC.

A. Vieira, F. Morgado Dias and A. M. Mota "Hybrid Neuro-Fuzzy Network-Priori Knowledge Model in Temperature Control of a Gas Water Heater System", 0-7695-2457-5/0 /2005, IEEE. 